\title{
Towards an Understanding of the Indian Tourist Buying Airbnb Services
}

Swati Sharma, Jaypee Institute of Information Technology, India

iD https://orcid.org/0000-0002-3260-8841

\section{ABSTRACT}

The business ecosystem has changed drastically. Advances in information technology, access to the internet, and pervasive use of mobile phones have given a spurt to various new age businesses adopting new business models. The empirical paper identifies the room sharing company as a new age platform business model. The study proposes and tests a conceptual model to study the factors influencing the consumers' attitudes towards Airbnb and their intention to purchase the services of Airbnb. The findings reveal that hedonistic values, social values, and financial value, along with e-word of mouth have a direct impact on consumers' attitudes towards Airbnb. Existing available literature is largely in the Western context and qualitative in nature. This paper is unique as it adopts a quantitative approach and provides insight about what really influences the consumers' attitudes towards this new and unique business model, thus enabling marketers to strategize accordingly.

\section{KEYWORDS}

Airbnb, E-Word of Mouth, Financial Value, Hedonism, Materialism, Social Value, Tourism, Utilitarianism

\section{INTRODUCTION}

New age businesses have changed the business scape of today. The technology disruptions have drastically transformed the way the businesses are done nowadays. Technological disruption and start-up are the buzzwords. Traditional businesses across all industries for example media, banking, hospitality, logistics, transportation are now feeling threatened by new technology enabled business models. The success of new age companies, like Uber, Airbnb, Netflix, Trivago, Oyo rooms are the new found interest of the consumers and are forcing established organizations to adapt and use the latest technology to re-invent themselves. New age businesses are using strategic business models to gain strategic and competitive edge. This empirical paper in the Indian setting discusses the new platform business model of Airbnb and explores the consumers' attitude towards buying Airbnb services. The paper starts with the discussion on emerging business models and in-depth literature review on the past work done on Airbnb. Lack of much published work in Indian context is the motivation behind the research work. The paper using descriptive research explores the prospective consumers' attitude towards buying Airbnb services and presents the empirical findings, conclusion and implication. 


\section{BACKGROUND LITERATURE}

Since last decade ICT and emerging business models have been a subject of interest among academicians (Baden-Fuller, \& Haefliger, 2013). The new age organizations aim at models that have an element of innovation and market orientation, which consequently gives business a strategic and competitive edge. This brings to desk the discussion on innovation in business models. Business model innovation is the adoption of a new business model in an already existing business (Markides, 2006), for example Amazon in retail, Uber, Ola in taxi services, Airbnb in room renting services, Paytm in digital wallets. Business model innovators redefine the attributes of the existing product and service by using new technologies/platforms to capitalize on it. Jo caudron and D. V Peteghem in their book “Digital Transformation" list out few emerging business models such as subscription model (locking in repeat customer by subscription fee e.g. Netflix, freemium model where the users have free access and in turn their data is used (LinkedIn), free model where users have free access and money flows in from advertising (Facebook), or digital marketplace (eBay, amazon) to name a few. Disruptive technology has been a catalyst to new business models. These technological advancements shake the conventional wisdom of the old stalwarts and their inability to adapt to the new model (Rosenbloom, Christensen, 1994) gives rise to new age companies with innovative business models.

"What is yours is mine" is the sobriquet that is used for the millennial. They believe in sharing of goods and services rather than owning it (Bardhi \& Eckhardt, 2012). Massive success of Zip car, Uber, Airbnb prove that this trend is here to stay. The tendency or belief in sharing has stimulated peer to peer based activity of sharing of goods and services which is enabled by Web 2.0 and Information technology advancement through sharing platforms. Although sharing has been central to collectivist societies, his business model is new and disruptive. The sharing of goods and services is an age-old phenomenon; the key enabler to this marketplace operating at scale has been the technology enabled platforms that facilitate far more of these transactions. The sharing platforms have virtually made the world one flat market space bringing together the buyers and seller dyad.

These technologies enabled business models are disruptive as it poses serious threat to traditional business. This paper discusses Airbnb under the platform model of room renting. This is an online community market space facilitating rentals ranging from shared accommodations to entire homes that has now contributed more than ten million worldwide bookings. Airbnb hosts rent out their properties or rooms to the prospective guests who use the website to find options for staying in their desired location. Airbnb's has a distinct appeal, which hovers on economical options for accommodation, household facilities, and an opportunity for more authentic local experiences. These features have led to the phenomenal growth of this company in the western countries. Airbnb boasts of currently offering listings in 191 odd countries (Airbnb.com) with US, France, Italy and Spain leading on the list. The revenue is generated through service fees from the guest and hosts, was valued at 31 billion U.S. dollars in May 2017. At this stage it becomes imperative for us to understand how India, one of

Figure 1. Popularity of Airbnb USA and Airbnb India (Source: Google Trends)

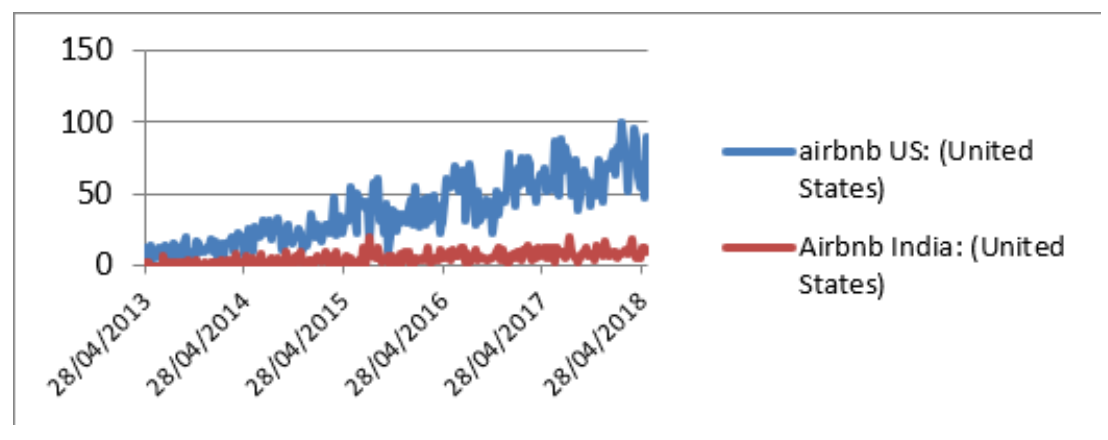


the biggest market of south east Asia, currently undergoing tumultuous times under heightened craze of start-ups perceives Airbnb. The figure below shows the popularity of Airbnb US and Airbnb India collected from Google trends as collected on May 25, 2018.

As seen from the figure the company is trending and the interest chart is steadily on the rise. This disruptive business capitalises on its platforms which assist the people with extra space to rent it out and on the other hand assists the consumers to use this space (room let out by owner) and enjoy the experience of home away from home. A close scrutiny reveals that Airbnb has not been able to make a foray in India, however the trend curve for Goa- a haven for western tourists witnesses surges above metropolitan cities like Mumbai and Delhi. This makes it imperative to study the perceptions of residents of such commercial cities regarding the new rage -Airbnb.

\section{PAST STUDIES ON AIRBNB}

Airbnb has elicited interest among researchers and extant literature especially in the context of western countries is widely available. Many researchers have gone to prove that this technology enabled business model is disruptive and is a catalyst in the growth of informal tourism (Guttentag, (2015). and has impacted hotel businesses (Zervas et al., 2017) and is not a fad but a trend which is here to stay (Varma et al., 2016). This new business model has already gained acceptance and is impacting the business of traditional budget hotels (Zervas et al., 2017) but has been widely criticised for regulatory loop holes and have emphasized on the need of regulatory frame work and standard policy (Edelman, \& Geradin, 2015; Quattrone et al., 2016,) and service quality (Priporas et al., 2017). Airbnb has attracted studies from the host perspectives i.e. host performance (Xie and Mao 2017), their motivation to list their properties on Airbnb (Lampinen \& Cheshire, 2016), determining the price their properties at Airbnb site (Wang \& Nicolau, 2017). Studies from the Airbnb user's perspective also find some place in the existing literature. Ert et al.,2016, emphasized the importance of trust and reputation in generating bookings and businesses. They found that the presence of hosts pictures affects the customers level of trust and consequently its intention to buy the services. Few researchers have explored on how consumer perceptions about Airbnb are affected by various advertising appeals and branding strategies (Liu \& Mattila, 2017). Besides users and host perspectives, researchers have explored the impact of this new business model on the local community (Guttentag, 2015) and identified it as a source of employment for locals (Fang, \& Law, 2016).

To summarize, the studies on Airbnb have been done from the perspective of users, hosts and local community as stake holders but only in the western context. Studies in the context of developing nation are still in nascent stage. In developing countries, it is seen as a unique concept and therefore, it's important to explore how well it is received by the residents of developing nation. This empirical paper fills in this gap and explores the factors that may influence the consumers' attitude towards Airbnb. Moreover, much of the work to date has been qualitative in nature; whereas this study takes a quantitative approach.

\section{A Case of India}

Indian society is collectivistic and values interdependence and social unity. This value system of Indian society is exhibited by its traditional extended or joint family system. The concept of sharing resources like rooms, clothes and meals etc are not new to Indian culture. However, the social fabric woven by interdependence, collectivism and restraint is changing, giving way to nuclear families. Therefore, in contrast to earlier theorization, research shows that Indians are also individualistic (Kapoor et al., 2003) and highly competitive (Ramamoorthy et al., 2007; Sinha et al., 2001) and value materialistic success. The economic liberalization, globalization, access to internet, and entrance of multinational corporations (MNCs) in India may have perhaps influenced a change in the value systems of the Indians (Ranganathan \& Lobo, 2008) by promoting consumerism and materialism, thus reinforcing competitive attitudes among the younger generations. This makes it interesting to 
explore the perceptions of people towards this emerging, business model of sharing homes. In addition to this, since the study is in the context of India- a sought after market by virtue of its sheer size and increasing GDP, thus making it imperative to understand the perception of these consumers.

\section{FACTORS THAT DETERMINE THE PURCHASE INTENTION OF NEW TECHNOLOGY ENABLED SERVICE}

This paper draws on two schools of thought: Technology adoption theory and Value based adoption model. Technology adoption model (Davis et al., 1989), theory of planned behaviour (TPB) (Azjen, 1991) have been widely used by many researchers to understand and predict user perceptions of system use and the probability of accepting a technology enabled service (Gefen et al.,2003) in contexts like adoption of mobile banking, mobile learning etc. However, in the case of Airbnb, the adopters are not just the technology users but also the end consumers. Airbnb consumers adopt the technology and use it voluntarily and also bear the cost involved (monetary and non-monetary). Therefore, for the end consumers of Airbnb it is imperative to delve into the perceived value delivered by Airbnb to the customers, which act as a triggering factor to shape the attitude and intention to buy the rental services. Consumers' perceived value of a product/service is an essential factor for all marketing activities (Holbrook, 1994). Value according to Zeithmal (1988), is overall assessment of the tradeoff between the quality received and the price paid. Consumers value timely and efficient delivery of products and services with minimal fallouts. Sheth et al. (1991) define consumption in context of functional value, social value, emotional value, epistemic value and conditional value. Sheth et al. (1991) promulgated that all or any of the five values may influence the consumption experience of a customer depending upon the situation. Holbrook (1994) proposed a typology of perceived value which includes eight types of value: convenience, quality, success, reputation, fun, beauty, virtue and faith. Both typologies aim at explaining the benefits a customer seeks to get from consumption however they do not take into account the price or costs associated with consumption. Value based adoption model (Kim et al., 2007) postulates that to adopt a (technology based) product or service the consumers maximize value and therefore the adoption decisions are based on by trading off between perceived benefits and perceived costs. It can be logically derived that when the consumers' weigh benefits more than the costs, they will develop favourable attitude towards product/services and adopt the same. Value plays a key role in consumer decision making and has been described in different ways such as hedonic value, utilitarian value (Eroglu et.al., 2005) and social value (Sweeney et al.1999). Deriving from the literature the author proposes that the value perceived by the consumer (hedonic, utilitarian and social) in addition to perceived risk (in terms of trust, quality of service and timely availability of service) would be the determining factors for building the consumers' attitude towards buying of Airbnb services. The study is based on the premise that consumers' favourable attitude towards a product or a service leads to subsequent purchase. This positive attitude-intention to purchase relationship was proposed by Ajzen and Fishbein, 1980 in TRA (theory of reasoned action). This relationship is also endorsed by other researchers like Ha and Janda, 2012.

\section{Hedonistic Values}

Hedonists are described as people engaged in the pursuit of pleasure and self-indulgent (McCracken, 1986). The rising disposable income and prosperity of the ever swelling middle income group has lead these consumers' to desire for the products and services for their symbolic aspect over their usefulness(Campbell, 2005). According to Hirschman and Holbrook, 1982, hedonist consumers enjoy the sensitive aspects of experience. As Airbnb offers various products and also a promise of new pleasure/experience of community interaction and personalized offerings (services). The people seeking for hedonistic pleasure will look for diversity in options and offerings rather than standardized hotel rooms and services. Thus, it can be hypothesized as: 


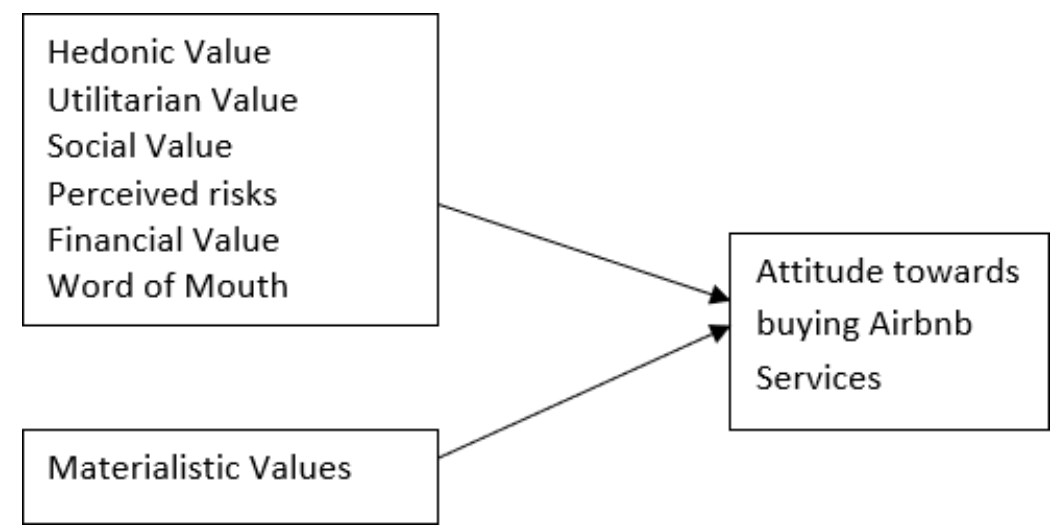

H1: There is a positive relationship between hedonism and consumers' attitude towards buying Airbnb service.

\section{Utilitarian Values}

Utilitarian is derived from the word utility meaning usefulness. Utilitarian values are extent to which a product/service performs the required functions and is useful for the consumer (Tynan et al., 2010). Utilitarian values emphasize rational focus on function and usage, unlike hedonistic values are concerned with emotional experience. Since Airbnb offer no frill accommodation options and are fulfil the basic functionality of bed and breakfast at affordable prices, it can be hypothesized as:

H2: There is a positive relationship between utilitarianism and consumers' attitude towards buying Airbnb service.

\section{Social Value}

Goods and services are often than not used for their social value. Consumers connect psychological meaning to products (Smith \& Colgate, 2007). The perceived social value of product /services is said to be high when the product enhances the consumers self-concept (Sweeney \& Soutar, 2001) and matches with the consumers' beliefs and values regarding societal conduct (Sharma, 2019; Blamey \& Braithwaite, 1997). In context of Airbnb, recognition or prestige obtained from adopting new age accommodation services may create social value (Williams \& Soutar, 2009) thus it can be postulated that:

H3: There is a positive relationship between social value and consumers' attitude towards buying Airbnb service.

\section{Perceived Risk}

Risks are the probability of occurrence of unfavourable events. Perceived risk is the consumer's subjective belief about the possibility for something to go wrong (Garbarino, \& Strahilevitz, 2004). In the context of Airbnb the consumers are apprehensive about various risks. These risks may influence the total perceived value negatively. Unlike Airbnb, hotel's star categorization communicates about expected quality. Consumer perceives risks regarding availability, and quality or service meted out 
to him by the host. Perceptions of risk will therefore have a negative relationship with attitude and purchase intention to buy Airbnb services.

H4: There is a negative relationship between perceived risk and consumers' attitude towards buying Airbnb service.

\section{Financial Value}

Price or monetary gains and losses are the key factor to influence the consumers purchase intentions. A mental calculation between the price paid and value received in the exchange process determines the buying intention of the consumers. Airbnb positions itself as low priced accommodation. For consumers who are price sensitive (Indians), economy accommodation option like Airbnb will have more financial value and therefore will trigger the buying process. Thus, it can be hypothesized as:

H5: There is a negative relationship between financial value and consumers' attitude towards buying Airbnb service.

\section{Electronic Word of Mouth}

Electronic word of mouth (e-WOM), as defined by Hennig-Thurau et al. (2004) is any "any positive or negative statement made by potential, actual, or former customers about a product or company, which is made available to a multitude of people and institutions via the Internet' Electronic age has benefitted consumers by providing a free platform to share reviews of products and services availed (Steffes \& Burgee, 2009). Reviews or word of mouth through electronic medium reaches to a large number of consumers as it spreads the opinions through discussion forums, websites and allows communication between consumers. In the context of Airbnb, the ambiguities related to the product (the accommodation) and services (interaction with and host and local community) are high. Therefore, it is logical for the consumer decision to be swayed by the online positive or negative reviews, or electronic word of mouth (Hernández, 2015). The literature has established a relationship between e-WOM and consumer attitude (Cheng et al., 2012) and purchase intention (Chevalier \& Mayzlin, 2006).

H6: There is a relationship between electronic word of mouth and consumers' attitude towards buying Airbnb service.

\section{Materialistic Values}

One factor that may define the acceptance of using low cost economy rental services is the importance they give to materialism. Materialistic people value material objects as ownership of objects of desire is a part of their identity (Shrum et al., 2013). Marketing researchers have been interested in the concept of materialism and have contributed to the development of the concept. Richins \& Dawson (1992) identified Materialism with three dimensions i.e acquisition centrality (the importance of ownership of possessions); acquisition in the pursuit of happiness; and lastly defining success by physical possessions. Materialistic consumers experience more positive affect and report increases in life satisfaction when consuming luxury products (Hudders \& Pandelaere, 2012), and elicits positive emotions such as joy, excitement, contentment and optimism (Richins, 2012). Materialistic consumers value material objects over spiritual and mental aspects. The unique selling proposition of Airbnb is socialization with the local hosts, at a unique place. Therefore, it can be said that materialistic consumers will desire to experience the new concept of staying and sharing accommodation with the host and thus hypothesized as: 
H7: There is a positive relationship between materialism and consumers' attitude towards buying Airbnb service.

\section{METHOD: MEASURES AND PSYCHOMETRIC PROPERTIES}

Utilitarian and hedonistic values were measured from a scale adapted from Voss et al. (2003). Social value was measured with three items adapted from Sweeney, \&Soutar, (2001), perceived risk was adapted from Forsythe et al. (2006).electronic word of mouth was measured by adapting the items from Jalilv \& Samiei (2012) and for financial value Irani and Hanzaee (2011). To capture the responses on materialism, Richins and Dawson scale was adopted (Richins \& Dawson, 1992). Before conducting the main survey, a pre-test was done to validate the instrument. The pre-test was done on 11 respondents. Respondents were asked to comment on the length of the instrument, the format, and the wording of the scales.

\section{Sampling Plan and Study Execution}

Purposive sampling was used and the data was collected from people who have travelled and love travelling to different places (domestic and international) and have booked accommodation (hotels, Airbnb and home stay). Respondents were contacted through various meet up groups and travel groups on social media to fill the questionnaire. In the initial phase of data collection, it was observed that many of the respondents had never experienced Airbnb and some had no idea about this concept as they had always been booked by their offices or travel agents in hotels. So, a small brief about the platform business concept along with pictures and websites was shown to each respondent, in order to make them understand the Airbnb concept. The data was collected by pen and paper method from 380 respondents from which 325 were found to be complete and were used for the study. The number of items and the cronbach alpha of the variables studied area as follows: hedonism $(\alpha=.815$, items $=3)$, utilitarianism $(\alpha=.729$, items $=2)$, social values $(\alpha=.645$, items $=3)$, perceived risk $(\alpha=.673$, items $=3)$, financial value $(\alpha=.661$, items $=3)$, and word of mouth $(\alpha=.768$, items $=4)$. For the materialism scale the items clubbed into three dimensions i.e centrality $(\alpha=.722$, items $=6)$, happiness $(\alpha=.753$, items $=4)$ and success $(\alpha=.769$, items $=6)$.

\section{DATA ANALYSIS}

The data analysis was done using SPSS16. To test the hypothesis Pearson correlation was computed. Regression analysis was done to study the impact of independent variables on the consumers' attitude towards buying Airbnb service. Consumers' attitude towards buying Airbnb was taken as dependent variable and independent variables were: hedonism, utilitarianism, social values, materialistic values, price, word of mouth and perceived risk.

\section{Descriptive Analysis}

Before determining the correlates and impact of the predictors of consumers' attitude towards Airbnb, mean and standard deviations were calculated, as this helps in understanding them better. The responses were captured on a 7-point scale with 7 as strongly agree and 1 as strongly disagree. The ranking of the dimensions based on the means and standard deviations is shown in Table1. It is clear from the table that financial value has the highest mean of $5.31(\mathrm{SD}=1.07)$, followed by electronic word of mouth $(\mathrm{m}=5.22, \mathrm{SD}=1.43)$. For the three dimensions of materialism the mean score of the dimension success is the highest at $4.5(\mathrm{SD}=1.08)$ and that of dimension -happiness is lowest at 3.95 with an SD of 1.35 . 
Table 1. Mean and Standard Deviation

\begin{tabular}{|l|l|l|}
\hline \multicolumn{1}{|c|}{ Dimensions of Value } & \multicolumn{1}{c|}{ Mean } & \multicolumn{1}{c|}{ SD } \\
\hline Financial Value & 5.31 & 1.07 \\
\hline e-Word of Mouth & 5.22 & 1.43 \\
\hline Hedoism & 4.89 & 1.06 \\
\hline Utilitarianism & 4.73 & 1.35 \\
\hline Social value & 4.56 & 1.31 \\
\hline Perceived Risk & 4.02 & 1.21 \\
\hline Materialism & Mean & SD \\
\hline Success & 4.51 & 1.08 \\
\hline Centrality & 4.37 & 1.04 \\
\hline Happiness & 3.95 & 1.35 \\
\hline
\end{tabular}

\section{Results and Discussion}

To test the hypothesis correlations between the dimensions of value and materialism with consumers' attitude towards Airbnb and their intention to purchase Airbnb services were computed. Five out of six dimension of value scale are significantly related to consumers' attitude towards Airbnb. It is observed from Table 2 that the e-word of mouth and perceived risk is significantly and negatively correlated with attitude towards Airbnb. It can be said that risk aversive Indian respondents, may perceive lack of trust, security and reliability and therefore have a negative correlation with the attitude towards Airbnb. Independent variable financial value had a positive but insignificant relationship with the consumers' attitude towards Airbnb. The relationship may not be significant but the direction reveals that if the perceived financial value is high the attitude will be favourable. The above discussion enables us to accept H1, H2, H3, H4, H6.

None of the dimension of materialism were found to be significantly correlated with attitude towards Airbnb, however it is to be noted that all the three factors shared negative relationship with the dependent variable thus enabling us to reject H6.

Table 2. Relationship (Correlation Coefficient) of Dimensions of Values and Materialism with Attitude towards Airbnb ( $N=325)$

\begin{tabular}{|l|l|}
\hline \multicolumn{1}{|c|}{ Values } & \multicolumn{1}{c|}{ Attitude towards Airbnb } \\
\hline Hedonism & $.335^{* *}$ \\
\hline Utilitarian Value & $.231^{* *}$ \\
\hline Social Value & $.316^{* *}$ \\
\hline Perceived Risk & $-.134^{*}$ \\
\hline Financial Value & 0.038 \\
\hline E word of mouth & $-.287^{* *}$ \\
\hline Materialism & Attitude towards Airbnb \\
\hline Centrality & -0.013 \\
\hline Happiness & -0.042 \\
\hline Success & -0.084 \\
\hline
\end{tabular}


A stepwise regression analysis was computed to examine the strength of the independent variables i.e. perceived value and materialism in predicting the dependent variable i.e. attitude towards Airbnb. It was assumed that there is a linear relationship between dimensions of perceived value, materialism (independent variables) and their probability to predict attitude towards Airbnb (dependent variable). Regression analysis is an important analysis, where the independent variables are used to define a dependent variable. A stepwise regression analysis was computed.

The results of regression analysis shows that five out of six determinants (value dimensions) have emerged as contributing significantly to the attitude towards Airbnb. The multiple regression model and overall fit statistics are depicted in Table 3. The study found that the R square of our model is 0.317 and multiple $\mathrm{R}$ is 0.563 . This means that the regression model explains $56 \%$ of the variance in the data. The beta values further expresses the relative importance of the independent variables in standardized terms. The positive and significant beta values of each of the variables- Hedonism, e-word of mouth, social value, and financial value, indicate that they all have a direct impact on attitude towards Airbnb. Out of the three dimensions of materialism, happiness has emerged as a negative determinant of attitude towards Airbnb. It may be observed that this did not have a significant correlation but in the regression analysis it has emerged as a significant determinant. Materialism was measured by dimension happiness i.e. fun or pleasure derived out of material possessions. It can be said that materialistic people who derive satisfaction and fun from material possession may not have a positive attitude towards sharing of accommodation spaces. Luxurious and branded accommodation options like renowned hotels will be their preference. All the three dimensions of materialism i.e. centrality happiness and success were negatively related to attitude towards Airbnb. Although the correlations were insignificant, the directional relationship is of great value. It can be said that the room rental company may not be preferred by materialistic people. The organizations need to find new positioning to attract the clients who are materialistic. Element of fun (hedonism), perceived utility and financial value are the important positive predictors of attitude towards Airbnb. The regression table reveals that the e word of mouth negatively impacts the attitude towards Airbnb. The dimension e word of mouth had items inquiring the customers on leaving reviews after a service experience and reading online reviews before buying the service experience. The negative correlation and negative beta values predict e-word of mouth as a negative determinant of attitude towards Airbnb. The Indian consumers who are risk aversive are more comfortable when the brand is known and brand name assures good quality service. However, in case of Airbnb, where it has yet not become a well-known brand, customers are sceptical and trusting on the online reviews is a blind leap of faith which the sceptical customers fear to take.

Table 3. Determinants of Attitude towards Airbnb ( $N=325$ )

\begin{tabular}{|l|l|l|l|}
\hline \multirow{2}{*}{ Independent Variables } & \multicolumn{2}{c|}{ Dependent variable: Attitude towards Airbnb } \\
\cline { 2 - 4 } & \multicolumn{1}{|c|}{ Beta(standardized) } & \multicolumn{1}{c|}{ Simple r } & \multicolumn{1}{c|}{ t-value } \\
\hline Hedonism & $.273^{* *}$ & $.335^{* *}$ & 4.681 \\
\hline E word of mouth & $-.403^{* *}$ & $-.287^{* *}$ & -8.203 \\
\hline Utilitarian & $.217^{* *}$ & $.231^{* *}$ & 4.113 \\
\hline Social Value & $.149^{* *}$ & $.316^{* *}$ & 2.796 \\
\hline Financial Value & $.174 * *$ & 0.038 & 3.512 \\
\hline Happiness(materialism) & $-.150^{* *}$ & -0.042 & -3.027 \\
\hline $\begin{array}{l}\text { Multiple R }=.563 \\
\text { R Square }=.317\end{array}$ & & & \\
\hline
\end{tabular}

Notes: ${ }^{* *} p<0.01,{ }^{*} p<0.05$ 


\section{CONCLUSION}

India is one of the fastest-growing outbound travel markets in the world. Despite drastic fluctuations in rupee value recently, numbers of outbound tourists' departures from India did not take a hit. India has emerged as the world's fastest-growing outbound market and in absolute numbers it is second only to China. With rising disposable income and interest in travel it becomes important to study the tourist's preferences in choosing their stays. Airbnb offers tourists an alternative to hotels. Airbnb has become prevalent in the hospitality and tourism industry. This company has grown at a rapid rate but its presence in India is still limited. Therefore, creating a need to understand what triggers adoption of Airbnb services by Indian consumers.

This study examines the influence of consumers' values on the adoption of Airbnb services.

The findings reinforce that consumers perceived value are responsible for the consumers' adoption of Airbnb services (Piscicelli, Cooper, \& Fisher, 2015).

The Indian consumers are price conscious (Khare et al., 2014), financial value and utilitarian value positively impact the consumers' attitude towards Airbnb. Hedonism and social value also positively impact the consumers' attitude towards adoption of Airbnb services (Lee \& Kim, 2018).

The study provides insights to Airbnb, present and prospective hosts and other room sharing service providers into the consumers mind. The organization (Airbnb) and the hosts therefore need to increase perceived social and price values and strategically communicate the same through various media channels. The organizations through integrated communication strategies should strive to create social value around the brand and its services. Materialistic people do not share a positive attitude towards Airbnb. Therefore, to woo the consumers high on materialism, initiatives to differently position the services are required.

\section{IMPLICATIONS AND LIMITATIONS}

The findings of the research have various implications. The respondents are highly materialistic (Table 1). Materialism is negatively correlated to attitude towards Airbnb and happiness in particular predicts negatively. Travelling is for fun. And in this age of social media the travellers love to share their experiences and tag their locations and place of stay. Materialistic people love to flaunt their luxurious abode during travelling as it is a sign of success. Airbnb does not elicit a feeling of pride and happiness among the users. The strategic marketers need to take this in view to decide the positioning of Airbnb. Positioning as "half the price of the hotel" may avert the potential customers. Although the potential customers hold financial value as most important and is one of the determinants of positive attitude towards Airbnb. Hedonism is the strongest predictor. Customers seek fun and experience while out on a tour. The strategic marketers may use this as their key strategy for positioning without undermining financial and utilitarian values. Social value also triggers positive attitude towards Airbnb, $\mathrm{e}$-word of mouth as a negative determinant signals that online reviews, and negative reviews create scepticism among consumers and the reviews act as deterrent to the adoption and purchase of services.

Although these research outcomes are insightful, the findings cannot be generalised. There are certain limitations that need to be acknowledged. Convenience sampling was used and the data was mainly collected from the twin cities Noida and Ghaziabad of the National Capital region. These twin cities are the new suburbs of the Indian capital Delhi and are a microcosm of India. However, a rich data collected from a wider region through random sampling is suggested for future research. It was also observed that though the respondents were avid travellers (as they were active on many travel groups) not many of them had heard or used Airbnb services. The perception regarding Airbnb and the value perceived may change when tested on respondents who have had an experience with Airbnb India. 


\section{REFERENCES}

Ajzen, I. \& Fishbein, M. (1980). Understanding attitudes and predicting social behaviour. Academic Press.

Baden-Fuller, C., \& Haefliger, S. (2013). Business models and technological innovation. Long Range Planning, 46(6), 419-426. doi:10.1016/j.1rp.2013.08.023

Bardhi, F., \& Eckhardt, G. M. (2012). Access-based consumption: The case of car sharing. The Journal of Consumer Research, 39(4), 881-898. doi:10.1086/666376

Blamey, R. K., \& Braithwaite, V. A. (1997). A social values segmentation of the potential ecotourism market. Journal of Sustainable Tourism, 5(1), 29-45. doi:10.1080/09669589708667274

Campbell, C. (2005). The craft consumer: Culture, craft and consumption in a postmodern society. Journal of Consumer Culture, 5(1), 23-42. doi:10.1177/1469540505049843

Cheung, C. M., \& Thadani, D. R. (2012). The impact of electronic word-of-mouth communication: Literature analysis and integrative model. Decision Support Systems, 54(1), 461-470. doi:10.1016/j.dss.2012.06.008

Chevalier, J. A., \& Mayzlin, D. (2006). The effect of word of mouth on sales: Online book reviews. JMR, Journal of Marketing Research, 43(3), 345-354. doi:10.1509/jmkr.43.3.345

Davis, F. D., Bagozzi, R. P., \& Warshaw, P. R. (1989). User acceptance of computer technology: A comparison of two theoretical models. Management Science, 35(8), 982-1003. doi:10.1287/mnsc.35.8.982

Edelman, B. G., \& Geradin, D. (2015). Efficiencies and regulatory shortcuts: How should we regulate companies like Airbnb and Uber. Stan. Tech. L. Rev., 19, 293. doi:10.2139/ssrn.2658603

Eroglu, S. A., Machleit, K., \& Barr, T. F. (2005). Perceived retail crowding and shopping satisfaction: The role of shopping values. Journal of Business Research, 58(8), 146-1153. doi:10.1016/j.jbusres.2004.01.005

Ert, E., Fleischer, A., \& Magen, N. (2016). Trust and reputation in the sharing economy: The role of personal photos in Airbnb. Tourism Management, 55, 62-73. doi:10.1016/j.tourman.2016.01.013

Fang, B., Ye, Q., \& Law, R. (2016). Effect of sharing economy on tourism industry employment. Annals of Tourism Research, 57, 264-267. doi:10.1016/j.annals.2015.11.018

Folkes, V. S., \& Kamins, M. A. (1999). Effects of information about firms' ethical and unethical actions on consumers' attitudes. Journal of Consumer Psychology, 8(3), 243-259. doi:10.1207/s15327663jcp0803_03

Forsythe, S., Liu, C., Shannon, D., \& Gardner, L. C. (2006). Development of a scale to measure the perceived benefits and risks of online shopping. Journal of Interactive Marketing, 20(2), 55-75. doi:10.1002/dir.20061

Garbarino, E., \& Strahilevitz, M. (2004). Gender differences in the perceived risk of buying online and the effects of receiving a site recommendation. Journal of Business Research, 57(7), 768-775. doi:10.1016/S01482963(02)00363-6

Guttentag, D. (2015). Airbnb: Disruptive innovation and the rise of an informal tourism accommodation sector. Current Issues in Tourism, 18(12), 1192-1217. doi:10.1080/13683500.2013.827159

Guttentag, D. A., \& Smith, S. L. (2017). Assessing Airbnb as a disruptive innovation relative to hotels: Substitution and comparative performance expectations. International Journal of Hospitality Management, 64, 1-10. doi:10.1016/j.ijhm.2017.02.003

Ha, H. Y., \& Janda, S. (2012). Predicting consumer intentions to purchase energy-efficient products. Journal of Consumer Marketing, 29(7), 461-469. doi:10.1108/07363761211274974

Habibi, M. R., Davidson, A., \& Laroche, M. (2017). What managers should know about the sharing economy. Business Horizons, 60(1), 113-121. doi:10.1016/j.bushor.2016.09.007

Hennig-Thurau, T., Gwinner, K. P., Walsh, G., \& Gremler, D. D. (2004). Electronic word-of-mouth via consumeropinion platforms: What motivates consumers to articulate themselves on the internet? Journal of Interactive Marketing, 18(1), 38-52. doi:10.1002/dir.10073 
Hernández-Méndez, J., Muñoz-Leiva, F., \& Sánchez-Fernández, J. (2015). The influence of e-word-of-mouth on travel decision-making: Consumer profiles. Current Issues in Tourism, 18(11), 1001-1021. doi:10.1080/13 683500.2013 .802764

Hirschman, E. C., \& Holbrook, M. B. (1982). Hedonic consumption: Emerging concepts, methods and propositions. Journal of Marketing, 46(3), 92-101. doi:10.1177/002224298204600314

Holbrook, M.B., (1994). The nature of customer value: an axiology of services in the consumption experience. Service quality: New directions in theory and practice, 21, 21-71.

Hudders, L., \& Pandelaere, M. (2012). The silver lining of materialism: The impact of luxury consumption on subjective well-being. Journal of Happiness Studies, 13(3), 411-437. doi:10.1007/s10902-011-9271-9

Irani, N., \& Hanzaee, K. H. (2011). The effects of variety-seeking buying tendency and price sensitivity on utilitarian and hedonic value in apparel shopping satisfaction. International Journal of Marketing Studies, 3(3). Advance online publication. doi:10.5539/ijms.v3n3p89

Kapoor, S., Hughes, P. C., Baldwin, J. R., \& Blue, J. (2003). The relationship of individualism-collectivism and self-construal's to communication styles in India and the United States. International Journal of Intercultural Relations, 27(6), 683-700. doi:10.1016/j.ijintrel.2003.08.002

Khare, A., Achtani, D., \& Khattar, M. (2014). Influence of price perception and shopping motives on Indian consumers' attitude towards retailer promotions in malls. Asia Pacific Journal of Marketing and Logistics, 26(2), 272-295. doi:10.1108/APJML-09-2013-0097

Kim, H. W., Chan, H. C., \& Gupta, S. (2007). Value-based adoption of mobile internet: An empirical investigation. Decision Support Systems, 43(1), 111-126. doi:10.1016/j.dss.2005.05.009

Lampinen, A., \& Cheshire, C. (2016, May). Hosting via Airbnb: Motivations and financial assurances in monetized network hospitality. In Proceedings of the 2016 CHI conference on human factors in computing systems (pp. 1669-1680). doi:10.1145/2858036.2858092

Lee, S., \& Kim, D. Y. (2018). The effect of hedonic and utilitarian values on satisfaction and loyalty of Airbnb users. International Journal of Contemporary Hospitality Management, 30(3), 1332-1351. doi:10.1108/ IJCHM-09-2016-0504

Liu, S. Q., \& Mattila, A. S. (2017). Airbnb: Online targeted advertising, sense of power, and consumer decisions. International Journal of Hospitality Management, 60, 33-41. doi:10.1016/j.ijhm.2016.09.012

Markides, C. (2006). Disruptive innovation: In need of better theory. Journal of Product Innovation Management, 23(1), 19-25. doi:10.1111/j.1540-5885.2005.00177.x

McCracken, G. (1986). Culture and consumption: A theoretical account of the structure and movement of the cultural meaning of consumer goods. The Journal of Consumer Research, 13(1), 71-84. doi:10.1086/209048

Piscicelli, L., Cooper, T., \& Fisher, T. (2015). The role of values in collaborative consumption: Insights from a product-service system for lending and borrowing in the UK. Journal of Cleaner Production, 97, 21-29. doi:10.1016/j.jclepro.2014.07.032

Priporas, C. V., Stylos, N., Rahimi, R., \& Vedanthachari, L. N. (2017). Unraveling the diverse nature of service quality in a sharing economy. International Journal of Contemporary Hospitality Management, 29(9), $2279-2301$. doi:10.1108/IJCHM-08-2016-0420

Quattrone, G., Proserpio, D., Quercia, D., Capra, L., \& Musolesi, M. (2016, April). Who benefits from the" Sharing" economy of Airbnb? In Proceedings of the 25th international conference on world wide web (13851394). doi: $10.1145 / 2872427.2874815$

Ramamoorthy, N., Kulkarni, S. P., Gupta, A., \& Flood, P. C. (2007). Individualism-collectivism orientation and employee attitudes: A comparison of employees from the high-technology sector in India and Ireland. Journal of International Management, 13(2), 187-203. doi:10.1016/j.intman.2006.11.002

Ranganathan, M., \& Lobo, B. (2008). Localizing the global: Analysis of nationalist ideologies in MNC advertisements in Indian TV. Nationalism \& Ethnic Politics, 14(1), 117-142. doi:10.1080/13537110701872709 
Reza Jalilvand, M., \& Samiei, N. (2012). The impact of electronic word of mouth on a tourism destination choice: Testing the theory of planned behavior (TPB). Internet Research, 22(5), 591-612. doi:10.1108/10662241211271563

Richins, M. L. (2012). When wanting is better than having: Materialism, transformation expectations, and productevoked emotions in the purchase process. The Journal of Consumer Research, 40(1), 1-18. doi:10.1086/669256

Richins, M. L., \& Dawson, S. (1992). A consumer values orientation for materialism and its measurement: Scale development and validation. The Journal of Consumer Research, 19(3), 303-316. doi:10.1086/209304

Rosenbloom, R. S., \& Christensen, C. M. (1994). Technological discontinuties, organizational capabilities, and strategic commitments. Industrial and Corporate Change, 3(3), 655-685. doi:10.1093/icc/3.3.655

Sharma, S. (2019). Journal of Environmental Accounting and Management. Journal of Environmental Accounting and Management, 7(4), 367-379. doi:10.5890/JEAM.2019.12.002

Sheth, J. N., Newman, B. I., \& Gross, B. L. (1991). Why we buy what we buy: A theory of consumption values. Journal of Business Research, 22(2), 159-170. doi:10.1016/0148-2963(91)90050-8

Sinha, J. B., Sinha, T. N., Verma, J., \& Sinha, R. B. N. (2001). Collectivism coexisting with individualism: An Indian scenario. Asian Journal of Social Psychology, 4(2), 133-145. doi:10.1111/j.1467-839X.2001.00081.x

Smith, J. B., \& Colgate, M. (2007). Customer value creation: A practical framework. Journal of Marketing Theory and Practice, 15(1), 7-23. doi:10.2753/MTP1069-6679150101

Steffes, E. M., \& Burgee, L. E. (2009). Social ties and online word of mouth. Internet Research, 19(1), 42-59. doi:10.1108/10662240910927812

Sweeney, J. C., \& Soutar, G. N. (2001). Consumer perceived value: The development of a multiple item scale. Journal of Retailing, 77(2), 203-220. doi:10.1016/S0022-4359(01)00041-0

Sweeney, J. C., Soutar, G. N., \& Johnson, L. W. (1999). The role of perceived risk in the quality-value relationship: A study in a retail environment. Journal of Retailing, 75(1), 77-105. doi:10.1016/S0022-4359(99)80005-0

Tynan, C., McKechnie, S., \& Chhuon, C. (2010). Co-creating value for luxury brands. Journal of Business Research, 63(11), 1156-1163. doi:10.1016/j.jbusres.2009.10.012

Van Boven, L. (2005). Experientialism, materialism, and the pursuit of happiness. Review of General Psychology, 9(2), 132-142. doi:10.1037/1089-2680.9.2.132

Varma, A., Jukic, N., Pestek, A., Shultz, C. J., \& Nestorov, S. (2016). Airbnb: Exciting innovation or passing fad? Tourism Management Perspectives, 20, 228-237. doi:10.1016/j.tmp.2016.09.002

Voss, K. E., Spangenberg, E. R., \& Grohmann, B. (2003). Measuring the hedonic and utilitarian dimensions of consumer attitude. JMR, Journal of Marketing Research, 40(3), 310-320. doi:10.1509/jmkr.40.3.310.19238

Wang, D., \& Nicolau, J. L. (2017). Price determinants of sharing economy based accommodation rental: A study of listings from 33 cities on Airbnb. com. International Journal of Hospitality Management, 62, 120-131. doi:10.1016/j.ijhm.2016.12.007

Williams, P., \& Soutar, G. N. (2009). Value, satisfaction and behavioral intentions in an adventure tourism context. Annals of Tourism Research, 36(3), 413-438. doi:10.1016/j.annals.2009.02.002

Xie, K., \& Mao, Z. (2017). The impacts of quality and quantity attributes of Airbnb hosts on listing performance. International Journal of Contemporary Hospitality Management, 29(9), 2240-2260. doi:10.1108/ IJCHM-07-2016-0345

Yannopoulou, N., Moufahim, M., \& Bian, X. (2013). User-generated brands and social media: Couchsurfing and Airbnb. Contemporary Management Research, 9(1), 85-90. doi:10.7903/cmr.11116

Zeithaml, V. A. (1988). Consumer perceptions of price, quality, and value: A means-end model and synthesis of evidence. Journal of Marketing, 52(3), 2-22. doi:10.1177/002224298805200302

Zervas, G., Proserpio, D., \& Byers, J. W. (2017). The rise of the sharing economy: Estimating the impact of Airbnb on the hotel industry. JMR, Journal of Marketing Research, 54(5), 687-705. doi:10.1509/jmr.15.0204 
International Journal of Asian Business and Information Management Volume $12 \cdot$ Issue $3 \cdot$ July-September 2021

Swati Sharma, serving as Associate Professor at JIIT Noida, has more than 20 years of work experience in Academics, Research and Industry. Her interest areas are Service Management Tourism and Technology adoptions. She has authored several refereed research papers in reputed research journals (SSCI \& SCOPUS indexed, $A B D C$ listed) including two A category journals with one publication in $A^{*}$ (IF-7.432). She can be contacted at sharma.a.swati@gmail.com. 